\title{
SCALING CHALLENGES OF HIGH-TECH SMES \\ DEVELOPING INTERNET OF THINGS TECHNOLOGY
}

\author{
Anthony Bouzakis, \\ Impact-BZ Ltd, London, United Kingdom \\ a.bouzakis@impact-bz.com
}

DOI: 10.36724/2664-066X-202I-7-2-2-6

\begin{abstract}
This paper is a review of the organizational structure and challenges that a technological enterprise faces during scaling, from the perspective of the engineering management. After expanding operations internationally, the distributed engineering teams developing hardware and software for internet of things applications, face issues regarding culture, communication, leadership, project planning and management. Relevant literature addressing these issues is presented. We elaborate on already implemented measures for improving the overall efficiency and propose further processes introduced in recent literature that can be beneficial for further optimizing the new product development. Potential knock-on effects by such implementation are also discussed.
\end{abstract}

KEYWORDS: Organizational Challenges; Scaling; Engineering Management; Manufacturing; Internet of Things. 


\section{INTRODUCTION}

The nowadays widespread use of technology covering all aspects of everyday life, sparked the proliferation of high-tech small and medium-sized enterprises (SMEs) developing IoT (internet of things) platforms. Though traditional SMEs may focus on steady growth, securing market share and establishing their local presence, hightech SMEs commonly follow the "start-up route" focusing on exponential growth and rapid scaling. This key difference between start-ups and traditional SMEs is mentioned in [1] with reference to how each structure gains access to funding opportunities. The exponential growth is typically tied with establishing international presence for various reasons beneficial to the organization.

A series of studies conducted by the European Commission confirm internationalization as a success factor for high-tech SMEs within Europe [2]. This is primarily because a multitude of technological products address niche markets and therefore accessing a broader potential customer base can be secured by expanding to international level. Moreover, by expanding internationally, an organization can gain access to skilled personnel or cost-effective labor, infrastructure, favorable political conditions, etc. that are otherwise unavailable to the primary location / head office. A typical example here would be a company designing clothing in a country famous for its fashion-designers and producing in an industrialized country with developed manufacturing infrastructure.

Any technological SME requires since its conception at least a few engineering roles (software, hardware, systems, sales, etc.) and a few functional roles (customer service, marketing, sales, human resources etc.). During international expansion, the former smaller team is now required to cooperate with other individuals or teams, which are more than often geographically separated and from different cultures. While there are processes and management models to accommodate a smooth integration, these are hard to implement when the expansion is rapid or are often overlooked by managers concentrated in the financial key performance indicators [3]. This can induce several fundamental organizational issues regarding communication, leadership and decision making.

\section{ORGanizational Structure, Growth State AND CURRENT ISSUES}

The company examined herein is an IoT-electronics manufacturer founded in the United Kingdom. The product portfolio comprises a series of electronic devices used in various industries, including oil and gas, military, car manufacturing, space exploration, data centers and logistics operators. The management team quickly established corporate presence in the United States, as it was considered a key market, and approached a venture capital firm while seeking funds for a rapid expansion. This led to the assembly of several functional teams spread all over the globe to serve the needs of the organization as illustrated in figure 1 .

\begin{tabular}{|c|c|c|c|c|}
\hline UK & China & India & USA & Germany \\
\hline Sales & Sales & Sales & Sales & Sales \\
\hline $\begin{array}{c}\text { Hardware } \\
\text { Engineering }\end{array}$ & $\begin{array}{l}\text { Hardware } \\
\text { Engineering }\end{array}$ & & $\begin{array}{c}\text { Hardware } \\
\text { Engineering }\end{array}$ & \\
\hline & & $\begin{array}{c}\text { Software } \\
\text { Engineering }\end{array}$ & $\begin{array}{c}\text { Software } \\
\text { Engineering }\end{array}$ & \\
\hline $\begin{array}{c}\text { Sales } \\
\text { Engineering }\end{array}$ & & & $\begin{array}{c}\text { Sales } \\
\text { Engineering }\end{array}$ & $\begin{array}{c}\text { Sales } \\
\text { Engineering }\end{array}$ \\
\hline $\begin{array}{l}\text { Customer } \\
\text { Service }\end{array}$ & & & $\begin{array}{l}\text { Customer } \\
\text { Service }\end{array}$ & \\
\hline Operations & & & Operations & \\
\hline IT & & & & \\
\hline Finances & & & Finances & \\
\hline & & & Marketing & \\
\hline
\end{tabular}

Figure 1. Organizational structure after initial growth stage

The company's initial head office located in the United Kingdom comprised two functional teams, namely a hardware engineering team and another for key administrative roles, employing a total of approximately 20 staff. The company eventually settled to the structure illustrated in figure 1, employing roughly 300 full-time staff, with all major restructuring taking place in a 12month timeframe. Though quantifying the growth level of the organization may not be very straightforward, by projecting the organizational structure onto the Greiner growth model, we can observe that the organization is running through phase 3 i.e., delegation [3]. This is tied with the creation of "profit centers", as illustrated by the establishment of regional sales offices in figure 1. Also, each regional structure tends to act more independently, focusing on their own performance. Moreover, senior management become less involved in the day-to-day business and communicate less frequently through formal corporate communication. As anticipated, this rapid restructuring resulted in leadership, communication, and decision-making conflicts, during the assembly of the regional units.

Though there are a few different perspectives, we will be focusing on the challenges faced by the distributed engineering teams. It is noteworthy that the product portfolio consists of 3 main categories:

- $\quad$ Active devices (hardware)

- $\quad$ Passive devices (hardware)

- Software

Active devices are battery supported electronics, while passive devices use ambient electromagnetic waves to operate. Software is sold either as a service (SaaS) supporting customer needs or as a product (SaaP), and mainly to assist applications for the electronic devices.

Figure 2 illustrates a simplified diagram of the new product development process, which is either driven by a market need as identified by senior management including operations, sales, and marketing (internal), or it is driven by a customer need as communicated to the engineering team through various channels including sales and sales engineering (external). Regarding the new product development process, the distributed engineering department follows the stage-gate model for hardware products, where the actual workload is split in different phases at the end of which continuation of the project is decided upon [4]. 


\begin{tabular}{|c|c|c|c|}
\hline $\begin{array}{c}\text { customer } \\
\text { driven }\end{array}$ & \multirow{2}{*}{$\begin{array}{c}\text { active } \\
\text { devices } \\
\sim 20 \text { staff }\end{array}$} & \multirow{2}{*}{$\begin{array}{l}\text { passive } \\
\text { devices } \\
\sim 30 \text { staff }\end{array}$} & \multirow{2}{*}{$\begin{array}{l}\text { software } \\
\sim 30 \text { staff }\end{array}$} \\
\hline $\begin{array}{l}\text { market } \\
\text { driven }\end{array}$ & & & \\
\hline & mechanical & mechanical & front end \\
\hline & antenna & antenna & back end \\
\hline & electronics & electronics & maintenance \\
\hline & firmware & QA and test & QA and test \\
\hline & QA and test & & \\
\hline
\end{tabular}

Figure 2. Engineering structure and new product development diagram

For software development the scrum model for the agile methodology is followed, where customer input (internal or external) is constantly fed to the engineering team and the product specifications are adapted accordingly [5].

Each product family requires the engagement of roughly 20 to 30 engineers, spanning various specializations as listed in figure 2. An engineering director is responsible for managing and distributing the engineering workload of each product family. The passive devices are managed by the UK Engineering Director, the active devices by US Engineering Director and the software products by the Software Engineering Director also located in the United States. The UK and US Engineering Directors report directly to the Chief Operations Officer (COO), while the Software Engineering Director reports to the US Engineering Director, who oversees all engineering functions in the US office (hardware and software).

However, not all engineering roles required for a specific product family are collocated. For example, all antenna engineers are part of the UK engineering team i.e., their work schedule is managed by the UK Engineering Director. Furthermore, software engineering is managed through the US office, whereas there is another team located in India as shown in figure 1. It is also apparent that the hardware engineering team in China mainly acts as an interface between the UK-US teams and manufacturing. Their goal is to assist the manufacturing team by transferring the development teams' designs into DFM specifications (design for manufacture) during the last stages of the new product development process.

The main issues arising due to this structuring are listed below:

- Engaging different cultures into collaborating

- Effective communication between distributed engineering teams

- Leadership - Deciding on engineering resource allocation

- $\quad$ Project planning and technology management

\section{ORgAnizATIONAL CUlture}

A fundamental issue that multinational companies face, regardless of size, is defining their organizational culture. Since the different regional structures are codependent and are required to work together, it is important to firstly quantify the individual organizational culture of each regional office and then based on the outcomes to define the culture of the organization as a whole. However, a summary of several studies indicates that quantifying organizational behavior is not straightforward and depends heavily on the industry [6].

\section{A. Effective Communicaiton}

A make-or-break factor that is crucial to the synergy between teams in international organizations is the spoken language. While a team of employees from different countries may not communicate as effectively as a team of employees from the same country, a study indicates that opting for informal language and face-toface meetings can help bridge the communication and cultural gap [7]. This study moreover recommends that the manager of a subsidiary be familiarized with the culture of the foreign country. A mixture of local and foreign employees within functional teams can also help increase productivity.

Another key factor for communication issues between the geographically separated teams is commonly the time zone difference. In some cases, this can work to the organization's advantage, as one team can pick up where the other one left off, whereas in other cases even a 1hour difference can be detrimental to the organization's operations [8].

\section{B. Leadership}

The effectiveness of the manager responsible for each regional team is crucial to the success of the that team. A study confirms that the member-site (regional structure) leadership is a critical factor influencing site culture and site performance, and that high-performing sites are more prone to initiating collaborative activities with other sites [9].

Though a management structure may be well defined, leadership is more important for achieving positive results and accomplishing goals in engineering projects. A study concluded that members from within the engineering team, demonstrating leadership behavior, are more important in agile environments for successful completion of development work [10]. A further study demonstrates that the performance of individual teams is directly affected by shared leadership within the teams, which is especially important for the overall prosperity of large organizations [11]. The driving factors fostering shared leadership within a team are trust, empowerment, age and maturity, fair reward, disposition and beliefs.

Therefore, it is necessary for managers to nurture product and project ownership among the individual members of the engineering teams for improving performance.

\section{Project planning and technology management}

The adoption of processes and digital tools is of paramount importance for facilitating the efficient execution of engineering projects. Employing highly skilled personnel is moreover crucial for these processes to be effective, as confirmed by an analytical study reviewing the degree of adoption of Industry 4.0 tools by Italian manufacturing SMEs [12].

Regardless of size, high-tech enterprises providing cutting-edge products or services have the intrinsic need for innovation to remain competitive on local or global scale. Though large multinational enterprises often 
allocate resources specifically for research and development purposes with dedicated departments, personnel and budget, smaller enterprises rely heavily on "open innovation' as introduced by [13]. This includes both the influx of innovation from external sources referred to as "technology acquisition", as well as the outflow of innovation incorporated in products and services referred to as "technology exploitation" [14]. Hence, the success of a high-tech SMEs is commonly tied with the exchange of relevant technical information with other organizations.

\section{RECOMMENDATIONS}

A significant issue arising in the examined enterprise is the communication between the hardware engineering teams and manufacturing. As mentioned in section (1.2), to alleviate this issue, a hardware engineering team was established inside the production facilities in China. This enabled the hardware engineering teams located in the UK and the US to effectively communicate their designs and receive feedback regarding manufacturing issues. Online meetings were arranged between the engineering teams so that issues and solutions could be communicated. Within this framework, we moreover suggest that these meetings be carried out more often and senior management allow more flexible working hours or home-officing to accommodate for the time zone difference between sites.

The engineering team in China was also given permission to independently solve design-formanufacture issues whenever possible, for avoiding time wasted until the team responsible for the initial design was available for revisions. Furthermore, the general manager of the Chinese site, who was originally employed in the UK office and offered long engineering experience was assigned to direct the local engineering team.

Among implemented tools and processes, we can identify the use of a global digital parts' database and the Stage Gate model for the development of hardware products, already showing a positive net effect and the scrum for the agile methodology proven to work effectively for software development.

The distributed software engineering teams in the US and India appear to work efficiently, with most issues being solved through regular online meetings, email communications and the use of business communication platforms, as for example "slack". A further tool that could be implemented to improve effective communication of project goals, deliverables and customer requests is the Obeya wall methodology. An excellent use this technique by Siemens, demonstrated improved performance of the development teams and higher engagement of all stakeholders [15].

Moreover, a combination of the Stage Gate and the Agile models could improve quality and reduce the overall time required for the development work for both hardware and software products, as indicated by [16]. This combination enables the segmentation of the development work through the Stage Gate model. Thus, the work is regularly reviewed to verify whether milestones have been met and senior management act upon to approve further allocation of resources. But also, by combining these features with the agile model, the development work shall be easier to adapt when customer feedback and requests are submitted to the engineering teams, thus leading to quicker convergence with customer expectations and higher customer satisfaction.

It was noted that the decision-making process during the initial phases of the new product development process could many times be convoluted. Though this is a common byproduct of the blue sky thinking that is an integral part of the brainstorming process leading to innovation, we propose the garbage can model for decision making. As originally proposed by [17] for better managing day-to-day issues, this model assumes a mix or random yet independent streams of problems, solutions, decision makers and choice opportunities to make decisions on any issue. A revised garbage can model using queues as introduced by [18] could be adapted for use within engineering team meetings.

It is noteworthy that the engineering management decision-making process could be optimized when allocating resources into the individual projects. As per a previously mentioned example in section (1.2), the US Engineering Director technically requires approval by the UK Engineering Director for using antenna engineers in active hardware development projects. The Balanced scorecard method with strategy maps as introduced by [19], could be implemented by senior and engineering management for long-term planning, assessing overall performance, deciding upon resource allocation, and communicating the organization's goals to the engineering teams.

\section{IMPLEMENTATION CONCERNS}

The establishment of the engineering team in China had a positive net effect, where the average time from design to finished product and the iterations required were significantly shortened, that led to the Chinese engineering team making even more independent decisions and to be recognized as an integral part to the new product development process. This is considered a positive implementation that helps with waste management, by reducing time required for production, used materials and other inefficiencies that eventually add cost to the final product [20]. We moreover proposed an increased participation in decision making by all engineers through shared leadership and better processes. A potential knock-on effect here would be the negative influence of team members, perceived to be more competent than they are.

A recent study shows that the general perception of competences is directly related to influence in decisionmaking on different types of issues [21]. Though this study focuses on employee representatives influencing management decisions and resolving issues when they arise, this illustrates that the perceived competence of team members plays a crucial role in decision-making, which may potentially have a negative effect. A typical example here would be a team member fluent in the organizations' formal communication language with less experience and technical skills, perceived to be more competent and thus having more influence in decision making than a counterpart not as fluent in the same language. 
We furthermore proposed the introduction of a combined Stage Gate and Agile process for the new product development process, based on its merits as described by [16]. However, sales or field application engineers are required for regular engagement with internal or external customers to provide input to the development team. [22] elaborate in their study on the concerns by senior managers regarding the required additional resources in sales engineering.

\section{CONCLUSIONS}

We herein review the organizational structure of a high-tech SME developing and manufacturing IoT hardware devices and software products. The reviewed enterprise underwent through the typical rapid expansion backed by venture capital, thus reaching a multinational status in a short period. This exponential growth incurred issues regarding culture, communication, leadership, project planning and management, which are commonly encountered in similar cases. The senior and engineering managers introduced several good practices, digital tools, and processes to address the key issues, with positive signs already showing. The enterprise appears to be on the right track to reach an initial public offering, an objective commonly shared by technological start-ups.

We propose some further improvements based on recent literature that should complement the existing processes by improving the overall efficiency of the organization. Though there are some potential knock-on effects, the proposed measures should be beneficial to the operation of the engineering teams and add value to the enterprise.

\section{REFERERNCES}

[1] R. Tech, "Startup Financing in Berlin," in Entrepreneurial Innovation and Leadership, N. Richter, P. Jackson and T. Schildhauer, Eds., Springer, 2018, pp. 65-75.

[2] E. Commision, "High-tech SMEs in Europe," European Commision, Brussels, 2002.

[3] G. van den Berg and P. Pietersma, Key Management Models, 3rd ed., Financial Times Publishind, 2016.

[4] J. F. Tesch, A.-S. Brillinger and D. Bilgeri, "Internet of Things Business Model Innovation and the Stage-Gate Process: An Exploratory Analysis," International Journal of Innovation Management, vol. 21, no. 5, 2017.

[5] A. Srivastava, S. Bhardwaj and S. Saraswat, "SCRUM model for agile methodology," International Conference on Computing, Communication and Automation, 2017.

[6] A. Bavik and T. Duncan, "Organizational Culture and Scale Development: Methodological Challenges and Future Directions," Nag Yan Business Journal, vol. 3, no. 1, pp. 55-66, 2014.

[7] P. Chitakornkijsil, "Intercultural Communication Challenges and Multinational Organization Communication," International Journal of Organizational Innovation, pp. 6-20, 2010.

[8] A. Sivunen, N. Nurmi and J. Koroma, "When a One-Hour Time Difference Is Too Much: Temporal Boundaries in Global Virtual Work," 49th Hawaii International Conference on System Sciences, pp. 511-519, 2016.

[9] E. Baker and M. Kan, "Developing a Collaborative
Network Organization: Leadership Challenges at Multiple Levels," Journal of Organizational Change, vol. 24, no. 6, pp. 853-875, 2011.

[10] E. Moore, "Influence of Large-Scale Organization Structures on Leadership Behaviors," in 2009 Agile Conference, Chicago, IL, USA, 2009.

[11] N. P. de Cruz, "A Conceptual Overview of Attaining, Maintaining, and Regaining Shared Leadership inn High Performing Teams," Journal of Leadership Education , vol. 18, no. 1, pp. 213-226, 2019.

[12] L. Agostini and R. Filippini, "Organizational and managerial challenges in the path toward Industry 4.0," European Journal of Innovation Management, vol. 22, no. 3, pp. 406-421, 2019.

[13] U. Lichtenthaler, "Open innovation in practice: an analysis of strategic approaches to technology transactions," IEEE Transactions of Engineering Management, vol. 55, pp. 148-157, 2008.

[14] H. Chesbrough, Open Innovation: The New Imperative for, Boston: Harvard Business School Press, 2003.

[15] R. K. Gupta, S. Jain and B. Singh, "Challenges in Scaling up a Globally Distributed Legacy Product," ACM / IEEE 13th International Conference on Global Software Engineering, pp. 72-76, 2018.

[16] R. G. Cooper and A. F. Sommer, "Agile-Stage-Gate for Manufacturers," Research-Technology Management, pp. 17-26, 2018.

[17] M. D. Cohen, J. G. March and J. P. Olsen, "A Garbage Can Model of Organization Choice," Administrative Science Quarterly, vol. 17, no. 1, pp. 1-25, 1972.

[18] P. W. Glynn, H. R. Greve and H. Rao, "Relining the garbage can of organizational decision-making: modeling the arrival of problems and solutions as queues," Industrial and Corporate Change, vol. 29, no. 1, pp. 125$142,2020$.

[19] L. Lucianetti, "The impact of the strategy maps on balanced scorecard performance," International Journal Business Performance Management, vol. 12, no. 1, pp. 2136, 2010

[20] O. Battaïa, A. Dolgui, S. S. Heragu, S. M. Meerkov and M. K. Tiwari, "Design for manufacturing and assembly/disassembly: joint design of products and production systems," International Journal of Production Research, vol. 56, pp. 7181-7189, 2018.

[21] A. B. Garcia, L. Munduate, P. Elgoibar, H. Wendt and M. Euwema, "Competent or Competitive? How Employee Representatives Gain Influence in Organizational Decision-Making," Negotiation and Conflict Management Research, vol. 10, no. 2, pp. 107-125, 2017.

[22] E. C. Conforto and D. C. Amaral, "Agile project management and stage-gate model - A hybrid framework for technology-based companies," Journal of Engineering and Technology Management, vol. 40, pp. 1-14, 2016.

[23] V. van de Vrande, J. P. de Jong, W. Vanhaverbeke and M. de Rochemont, "Open innovation in SMEs: Trends, motives and management challenges," Technovation, vol. 29, pp. 423-437, 2009.

[24] M. A. K. Basuony and M. N. El Guindy, "The Evolution and Applications of Balanced Scorecard: A Comparative Approach". 